\title{
Programming a Parametric Design Algorithm to Improve Manufacturing Processes' Efficiency: The Case Study of Glued-Laminated Timber
}

\author{
Gabriele Pasetti Monizza ${ }^{1}$, Dominik T. Matt ${ }^{1,2}$ and Cristina Benedetti ${ }^{2}$ \\ 1. Faculty of Science and Technology, Free University of Bozen, Bozen-Bolzano 39100, Italy \\ 2. Fraunhofer Italia, Bozen-Bolzano 39100, Italy
}

\begin{abstract}
In the last decade, parametric and generative design techniques become quite popular for form-finding strategies or for pushing automation in design processes. Nevertheless, these techniques could be applied in engineering processes as well in order to improve the effectiveness and the efficiency of manufacturing processes in BI (building industry). Focusing on the case study of GLT (glued-laminated timber), this paper shows the procedure of programming a parametric algorithm adopted by authors that pursues two specific design intents: reducing the usage of unneeded high-quality raw material and improving the efficiency of production processes by producing DF (digital fabrication) contents for standard production systems of GLT. According to different European and international standards, thanks to FEM (finite element model) simulations and curvature analysis, the algorithm allows saving at least $33 \%$ of high-quality raw material and, according to early first surveys on a standard production system, $30 \%$ of operation time among product engineering-processes.
\end{abstract}

Key words: Parametric and generative design techniques, glued-laminated timber engineering, manufacturing engineering.

\section{Introduction}

According to surveys by the ISTAT (Italian Institute of Statistics), BI (building industry) is the less efficient industry on the market and the gap with other manufacturing industries is growing faster [1].

This lack of efficiency is mainly due to the following reasons:

- BI is an ETO (engineer-to-order) industry, following the Wortmann classification [2], characterized by a rigid serial workflow among different responsible figures (designers, engineers, general contractors, facility managers, etc.) which could enhance a propagation of errors among the supply-chain system;

- Front-end strategies and tools are completely missing. So, any information management strategy to

Corresponding author: Gabriele Pasetti Monizza, Ph.D. candidate, research fields: low-energy buildings, timber engineering, parametric and generative design techniques and manufacturing engineering. prevent propagation of errors cannot be adopted.

\subsection{BIM Tools, Parametric and Generative Techniques} as Possible Solutions to Improve the Information Management in the BI

BIM (building information modeling) tools and parametric and generative design techniques have been introduced in order to push the BI toward a more reliable information management workflow [3].

BIM tools, according to the definition by the NBIMS-US (National BIM Standard-United States ${ }^{\circledR}$ ) Project [4], have to be intended as a collector of information and relationships between information only. This implies that these tools are effective in handling information that has been already defined. In other words, only if information and relationships are established, it is possible to apply them in BIM environments.

According to Jabi's definition [5], parametric design is "the process based on algorithmic thinking 
that enables the expression of parameters and rules that, together, define, encode and clarify the relationship between design intent and design response". This relationship is expressed through a connection between elements (components) that lead the manipulation and the generation of complex geometries and structures. Whether parametric algorithms use iteratively some components in order to identify the best solution to a specific design intent within design boundaries (parameters and rules), the process may be defined as generative design technique. Parametric and generative techniques are more effective in decision-making processes, in case of information and relationships that have to be defined [6, 7]. Nowadays, computers aid the algorithmic thinking, and script programming is the formal expression of design algorithms. Thanks to a uniform and explicit language (scripts), it is possible to efficiently manage information among different responsible figures in the value-chain system.

BIM tools, parametric and generative techniques have to be considered as complementary approaches (at different levels) to push a more efficient strategy of information management among different responsible figures in the overall value-chain system of the BI.

\subsection{Short Overview of Glued-Laminated Timber Technology}

Glued-laminated timber (also known as GLT or GLULAM) is the most ancient engineered wood product. Since from Leonardo da Vinci's studies until the official patent by Hetzer in 1905 [8], main purposes of this product are to enhance the mechanical performances and to increase the dimension limits of the raw material (wood). In order to fulfil these purposes, it is manufactured by bonding together selected timber elements (laminates) and reducing the natural defects of the raw material. Today, thanks to several innovations in bonding technologies, manufacturing processes and quality management, it is possible to manufacture almost any kind of shape (even a double-curved one) with high mechanical performances of the final product.

Across European countries, glued-laminated timber products are regulated by the EN 14080 standard [9]. This standard prescribes all the information needed to manufacture a performance-guaranteed product. Nevertheless, the approach suggested by the EN 14080 and the EN 1194 [10] standards is quite simplified and it provides optimal solution only for ordinary shapes such as straight products. In case of complex shapes, standard prescriptions do not allow any kind of optimization. According to EN 1194, it is allowed to bonding together different strength classes of laminates just in case of a uniform and clear distribution of principal stresses along the main section of a GLT element. The amount of lower strength classes of laminates cannot overcome the limit of $66 \%$ of the main section. This lack of optimization increases the usage of unneeded high-quality raw material and the overall cost of final products, especially for complex products such as doubled-curved ones.

According to Silly [11], the cost of the sawn timber increases by $40 \%$ since 2009. Nowadays, timber industry is looking for new strategies in order to reduce the usage of high-quality raw material (sawn timber). This paper describes and shows the procedure adopted by authors of designing an efficient information management workflow that aims at overcoming limitations in optimizations through parametric and generative design techniques.

\section{Programming a Parametric Algorithm to Optimize GLT Manufacturing}

The algorithm has to purse two specific design intents:

- reducing the usage of unneeded high-quality raw material;

- improving the overall efficiency of the production system of GLT without any change in the production system's machinery or layout. 
In order to fulfill these intents, the algorithm combines different optimization strategies suggested by international standards through four main steps (for a preliminary structure of the algorithm in Fig. 1):

- geometry analysis in order to identify key inputs for further steps;

- curvature analysis in order to perform specific optimizations on laminates' height;

- FEM simulation in order to identify axial stresses in a discrete domain;

- labelling of laminates in order to collect and arrange information for machinery on a standard production system (the so-called digital fabrication).

In order to preserve the general capability of an ETO industry like the GLT one, the algorithm has to be programmed in order to handle free-form inputs. Thus, it is possible to handle different requests time by time delivered by clients. According to an ordinary GLT manufacturing workflow, the algorithm has been programmed to require these inputs only:

- A 3D model of the structural element that has to be manufactured. The 3D model has to be a NURBS (non uniform rational basis-splines) solid or NURBS surfaces jointed together;

- Loads and supports as defined by an external structural analysis according to national or international standards.

As the first step, the algorithm performs a geometry analysis in order to identify key inputs for further steps such as planes of symmetry, length and width of the main section of the structural element, etc. This analysis is performed by deconstructing the input model. Through this deconstruction, the algorithm

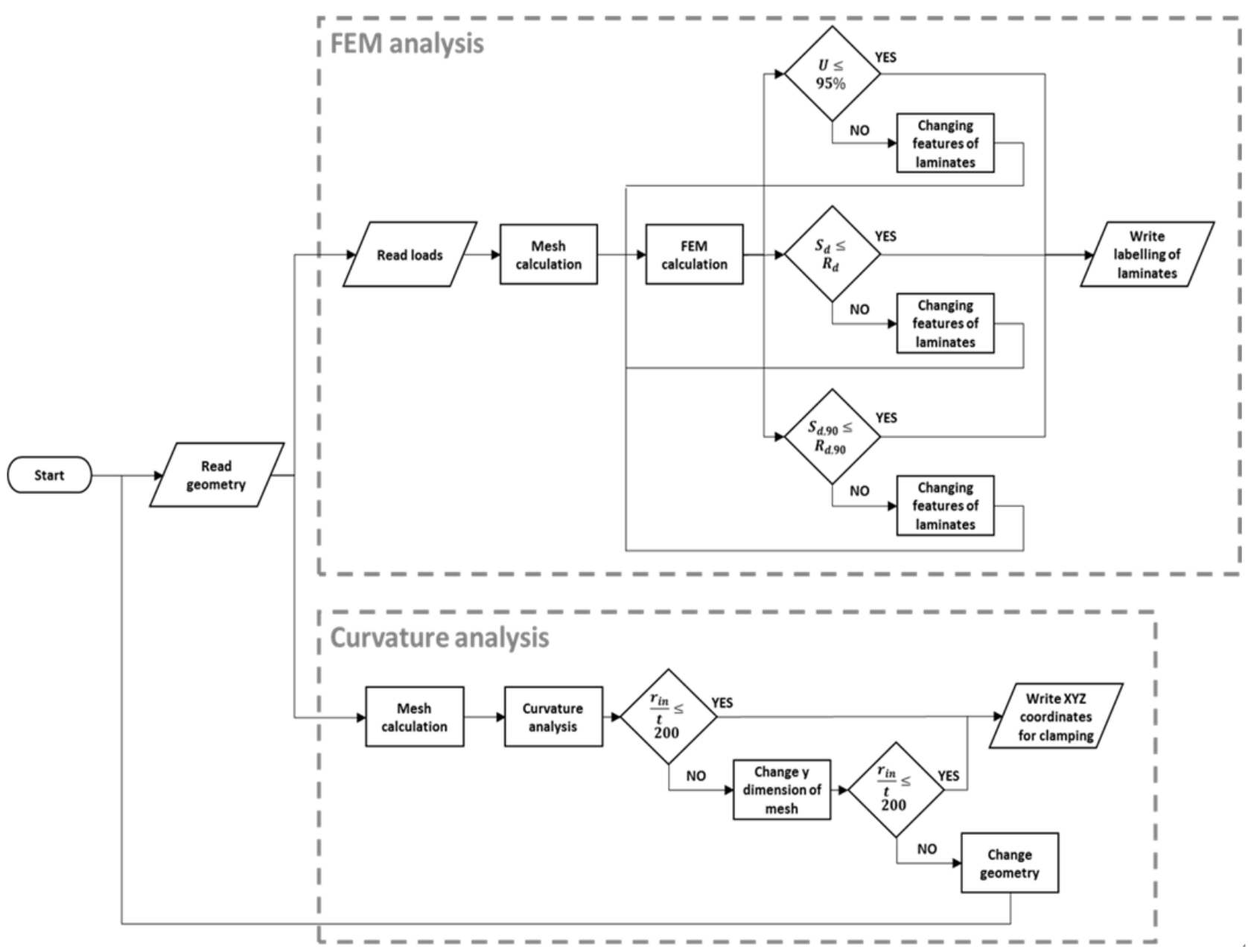

Fig. 1 Preliminary structure of the programmed algorithm. 
identifies surfaces according to their main plane $(\mathrm{XY}$, $\mathrm{XZ}$ or $\mathrm{YZ}$ ) and main curves of each surface (perimeter and axes of symmetry). Finally, referring to these main curves, the algorithm constructs planes of symmetry and identifies the main axis of the structural element, length and width of the main section. In order to reduce the overall complexity during first tests, the algorithm can only handle structural elements with constant section along the main axis.

For the second step, the algorithm performs a curvature analysis in order to introduce specific optimizations on laminates' height. The analysis is performed on the two main curvature planes (XZ, XY). The algorithm identifies the inner curvature radius according to a discretization interval defined by the user. The user defines also laminates' heights (conventionally from $20 \mathrm{~mm}$ to $50 \mathrm{~mm}$ ) in two main axes parallel to main curvature planes ( $\mathrm{Y}$ axis and $\mathrm{Z}$ axis). Finally, the algorithm identifies possible critical areas on the structural element for each main curvature plane according to the following relationship established by the DIN 1052 standard [12]:

$$
\frac{r_{i n}}{t} \geq 200
$$

where, $r_{\text {in }}$ stands for the inner curvature radius and $t$ for the laminates' height. The algorithms plots values of this relationship on planes of symmetry according to the discretization interval defined before.

As the third step, the algorithm performs an FEM simulation in order to identify axial stresses in a discrete domain. Once user has defined the discretization interval, loads, supports and their degrees of freedom, the algorithm performs the simulation according to a first-order shear deformation finite element model. Finally, the algorithms plots axial stresses values on surfaces located on the main plane parallel to the main axis of the structural element (XZ).

In the fourth step, the algorithm performs a labelling of laminates identifying their strength classes and their position along the structural element. Starting from the axial stresses values previously calculated, the algorithm identifies strength classes according to the following relationship:

$$
\sigma_{d} \leq f_{d}
$$

where, $\sigma_{d}$ stands for the principal axial stress applied to the discretized element (MPa) and $f_{d}$ for the design axial strength of the element (MPa). The design axial strength has to be calculated according to Eq. (3) as established by the EN 1995-1-1 standard [13]:

$$
f_{d}=k_{\text {mod }} \cdot \frac{f_{m, g, k}}{\gamma_{m}}
$$

where, $k_{\text {mod }}$ stands for a coefficient that considers the load duration and the humidity of elements as defined by EN 1995-1-1 standard, $f_{m, g, k}$ for the characteristic bending resistance of the material (MPa) and $\gamma_{m}$ for a safety coefficient as defined by EN 1995-1-1 standard.

According to EN 1194 standard, the characteristic bending resistance of GLT can be calculated starting from the nominal axial strength of laminates as follow:

$$
f_{m, g, k}=7+1.15 f_{t, 0, k}
$$

where, $f_{t, 0, k}$ stands for the nominal axial strength of laminates (MPa). Table 1 shows values of the design axial strength $\left(f_{d}\right)$ per strength class of laminates according to Eqs. (3) and (4), considering a $k_{\text {mod }}$ equal to 0.6 and $\gamma_{m}$ equal to 1.25 .

According to Weibull theory [8], the characteristic strength of the material could be increased considering a size effect for sections of the structural element smaller than sections used for standard strength tests. Thus, whether the section's height is smaller than 150 $\mathrm{mm}$, the algorithm can apply an amplifying coefficient to the nominal axial strength of laminates $\left(f_{t, 0, k}\right)$ as established by the EN 1995-1-1 standard and the Italian National Structural Code [8] and calculated according to Eq. (5): 

The Case Study of Glued-Laminated Timber

Table 1 Design strength per strength class of laminates with $k_{m o d}$ equal to 0.6 and $\gamma_{m}$ equal to 1.25 .

\begin{tabular}{llll}
\hline $\begin{array}{l}\text { Strength class } \\
\text { (EN 338) }\end{array}$ & $\begin{array}{l}f_{t, 0, k} \\
\text { (EN 388) }\end{array}$ & $\begin{array}{l}f_{m, g, k}(\mathrm{MPa}) \\
\text { C14 }\end{array}$ & $f_{d}$ (MPa) \\
C16 & 10 & 16.2 & 7.776 \\
C18 & 11 & 18.5 & 8.88 \\
C20 & 12 & 19.65 & 9.432 \\
C22 & 13 & 20.8 & 9.984 \\
C24 & 14 & 21.95 & 10.536 \\
C27 & 16 & 23.1 & 11.088 \\
C30 & 18 & 25.4 & 12.192 \\
C35 & 21 & 27.7 & 13.296 \\
C40 & 24 & 31.15 & 14.952 \\
C45 & 27 & 34.6 & 16.608 \\
C50 & 30 & 38.05 & 18.264 \\
\hline
\end{tabular}

$$
k_{h}=\min \left\{\left(\frac{150}{h}\right)^{0,2} ; 1,3\right\}
$$

where, $h$ stands for the section's height (mm) of the structural element under bending stress.

Although the algorithm completely identifies all information needed for manufacturing a GLT element, authors would remark that it has not been possible to fully implement a digital fabrication strategy. In order to do so, specifications for input data of machinery along a production system have to be defined. Considering that companies usually adopt different machineries case by case, a full implementation of digital fabrication step has to be postponed case by case according to machineries' specifications. Considering this lack in implementing the digital fabrication strategy, the following section discusses results of applying the programmed algorithm to selected structural elements as testing cases: a straight element and a double curved one. The straight element has been used as a testing case for a simple validation of results. The double curved element has been used in order to fully test the capabilities of the algorithm fulfilling design intents.

\section{Testing the Programmed Algorithm}

\subsection{First Test Case}

The first test case is a simply supported element with a total span of $5 \mathrm{~m}$ and a section of $120 \times 196$ mm (Fig. 2). Appling a line load of $2.7 \mathrm{kN} / \mathrm{m}$, it is possible to calculate the maximum bending moment as:

$$
M_{d}=q \cdot \frac{l^{2}}{8}=2.7 \times \frac{52}{8}=8.44(\mathrm{kN} \cdot \mathrm{m})
$$

where, $q$ stands for the line load $(\mathrm{kN} / \mathrm{m})$ and $l$ for the total span (m). Thus, the maximum principal axial stress can be calculated according to Eq. (7):

$$
\sigma_{d}=\frac{M_{d}}{W}=\frac{8.44 \times 10^{6}}{\left(\frac{120 \times 196^{2}}{6}\right)}=10.99(\mathrm{MPa})
$$

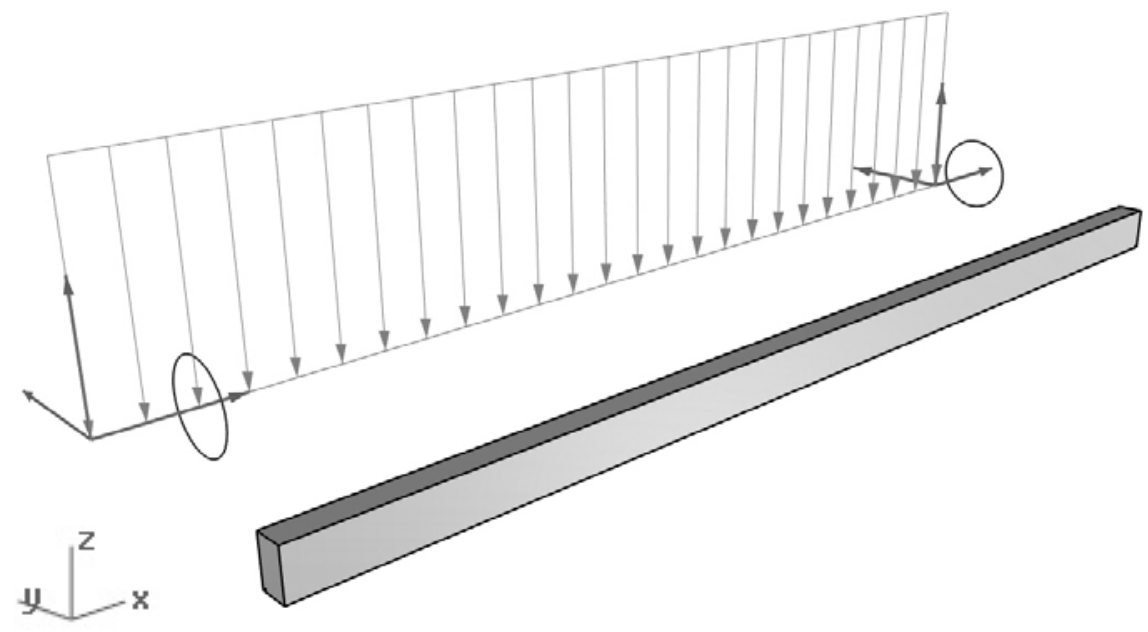

Fig. 2 Configuration of the first test case. 
where, $W$ stands for the resistance modulus of the section $\left(\mathrm{mm}^{3}\right)$.

Considering a $k_{\bmod }$ equal to 0.6 and a $k_{h}$ calculated according to the EN 1995-1-1 standard and to the Italian National Structural Code, slightly different from Eq. (5) for GLT products, it is possible to identify that the structural element should be a GL24c element in order to respect the condition of Eq. (2). A GL24c element is a GLT element manufactured by bonding together two strength classes of laminates: C24 and C16, respectively, following the classification suggested by the EN 388 standard. According to the EN 1194 standard, the composition of laminates can be calculated approximately, for this test case, as $66 \%$ of the section with C24 strength class laminates and 33\% of the section with C16 strength class laminates, considering a laminates' height equal to $32 \mathrm{~mm}$.

Appling the first test case to the programmed algorithm, the algorithm calculates a stress distribution and identifies the minimum strength class of laminates as shown in Fig. 3. For this test case, considerations about curvature analysis have to be neglected. According to these results, the maximum principal axial stress is equal to $11.21 \mathrm{MPa}$ and the composition of laminates is: $33 \%$ of the section with C24 strength class laminates and $66 \%$ of the section with C14 strength class laminates. All intermediate strength classes have to be neglected, considering that, nowadays, it is not possible yet to manufacture heterogeneous laminates along their principal axis. Table 2 shows the complete composition of laminates along the GLT element as calculated by the programmed algorithm.

Although the value of the maximum principal axial stress is similar to the value calculated in a definitive way according to Eq. (7), it is possible to save the $33 \%$ of high-quality raw material through the programmed algorithm, even introducing limitation in manufacturing of GLT.

\subsection{Second Test Case}

The second test case is a simply supported double-curved element—randomly generated — with a total span of $10.10 \mathrm{~m}$ and a section of $240 \times 400 \mathrm{~mm}$ (Fig. 4).

Appling a line load of $8 \mathrm{kN} / \mathrm{m}$, the algorithm calculates a stress distribution and identifies the minimum strength class of laminates as shown in Fig. 5. The double curvature generates an eccentricity of the line load which produces a residual torsion effect on the main section. Thus, results are different on the two main planes XZ of the element. According to these results, the maximum principal axial stress is equal to $14.87 \mathrm{MPa}$. This value may be accepted as correct referring to results from the first test case without further validations adopting definitive methods.
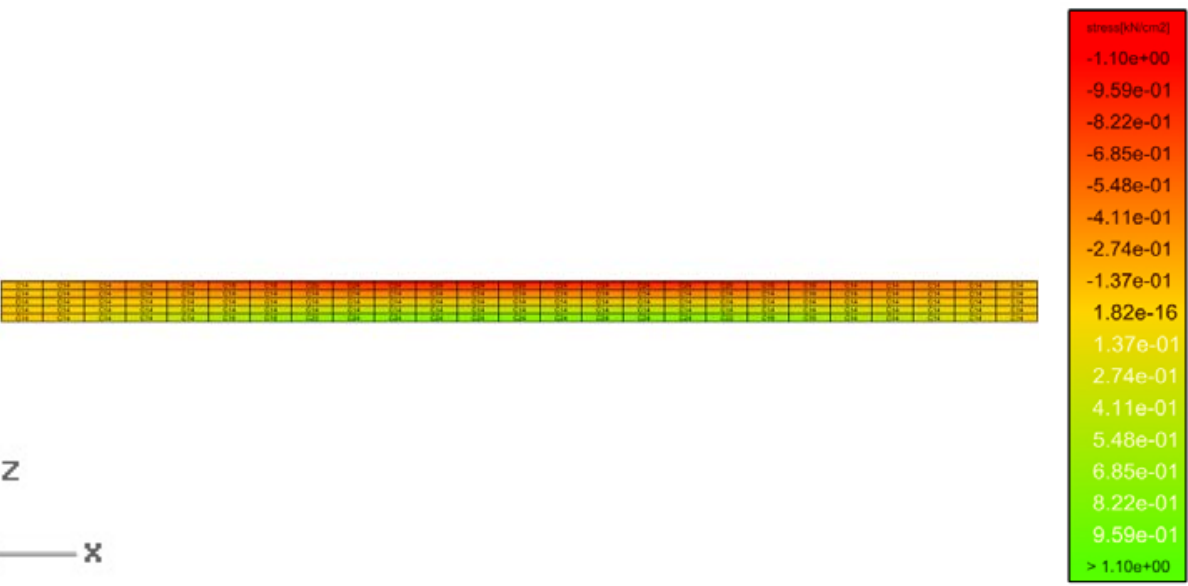

Fig. 3 Results for the first test case as calculated by the programmed algorithm. 
Table 2 The complete composition of laminates along the GLT element as calculated by the programmed algorithm for the first test case.

\begin{tabular}{ll}
\hline Strength class (EN 338) & $\%$ \\
\hline C14 & 82.86 \\
C16 & 2.29 \\
C18 & 2.29 \\
C20 & 1.14 \\
C22 & 1.14 \\
C24 & 10.29 \\
\hline
\end{tabular}

According to the EN 1194 standard, the composition of laminates must be homogenous because it is not possible to identify a uniform and clear distribution of principal stresses along the main section of the element. Thus, considering a maximum principal axial stress equal to $14.87 \mathrm{MPa}$, the structural element should be a GL32h element in order to respect the condition of Eq. (2). A GL32h element is a GLT element manufactured by bonding together C35 strength class laminates only.

The programmed algorithm identifies a complete composition of laminates as shown in Table 3. Introducing manufacturing limitation, the composition of laminates changes as shown in Table 4. According to these results, the programmed algorithm allows saving the $50 \%$ of high-quality raw material even introducing limitation in manufacturing of GLT.

Appling the condition of Eq. (1), the programmed algorithm does not highlight any critical area for the curvature plane XZ (Fig. 6), considering a laminates' height of $40 \mathrm{~mm}$ along the $\mathrm{Z}$ axis. On the curvature plane $\mathrm{XY}$, the programmed algorithm highlights a critical area considering a laminates' height of $40 \mathrm{~mm}$

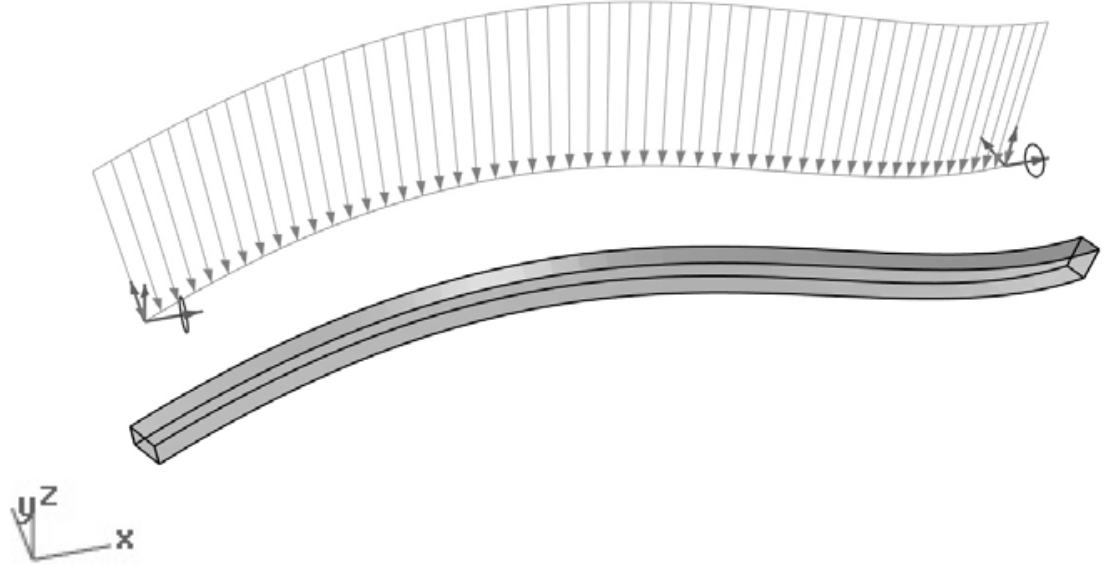

Fig. 4 Configuration of the second test case.

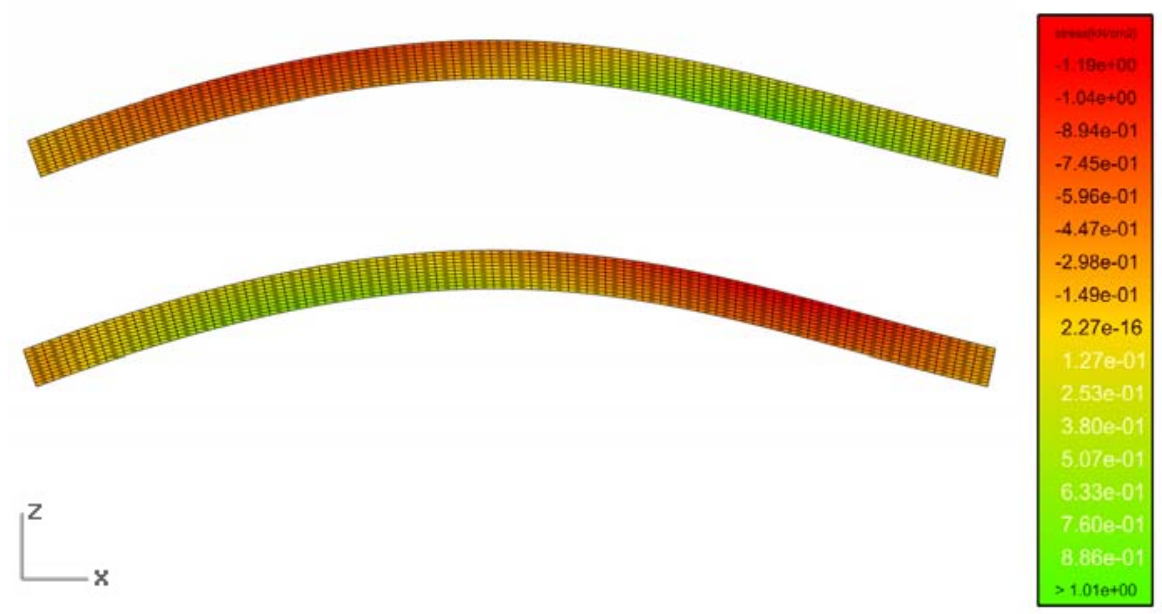

Fig. 5 Results for the second test case as calculated by the programmed algorithm 
Table 3 The complete composition of laminates along the GLT element as calculated by the programmed algorithm for the second test case.

\begin{tabular}{ll}
\hline Strength class (EN 338) & $\%$ \\
\hline C14 & 70.19 \\
C16 & 5.62 \\
C18 & 7.24 \\
C20 & 3.33 \\
C22 & 1.24 \\
C24 & 3.05 \\
C27 & 3.43 \\
C30 & 2.57 \\
C35 & 3.33 \\
\hline
\end{tabular}

Table 4 The composition of laminates along the GLT element introducing manufacturing limitations, as calculated by the programmed algorithm for the second test case.

\begin{tabular}{ll}
\hline Strength class (EN 338) & $\%$ \\
\hline C27 & 30 \\
C30 & 20 \\
C35 & 50 \\
\hline
\end{tabular}

along the $\mathrm{Y}$ axis (Fig. 6). According to further analysis performed by the programmed algorithm, the minimum laminates' height along the $\mathrm{Y}$ axis should be equal to $30 \mathrm{~mm}$ in order to respect the condition of Eq. (1). Optimizations can be introduced depending on specific strategies and capabilities of each GLT producer. Thus, output data from curvature analysis can be adopted in different ways:

- The element can be manufactured in two different pieces with two different laminates' heights along the $\mathrm{Y}$ axis. These pieces can be jointed together by gluing them or through a mechanical steel connection;

- The element can be assembled, in a first stage, by cramping together laminates (full-section wide-240 $\mathrm{mm}$ for the second test case) according to the first curvature plane XZ. On a second stage, the curved element has to be cut along the plane $\mathrm{XZ}$ obtaining heterogeneous curved laminates with a height of $30 \mathrm{~mm}$. Finally, the double-curved element can be manufactured by cramping together heterogeneous curved laminates according to the second curvature plane XY.

\section{Conclusions and Future Developments}

Parametric and generative design techniques can be considered an effective tool for enhancing capabilities of design and engineering processes and for improving the efficiency of manufacturing processes in the BI. Referring to the case study of GLT products, results show that raw-material savings can reach $70 \%$. Due to some limitations in manufacturing capabilities, savings have to be reduced. These limitations could be easily overcome by introducing software updates on machineries and some changes of layouts in early production system's processes.

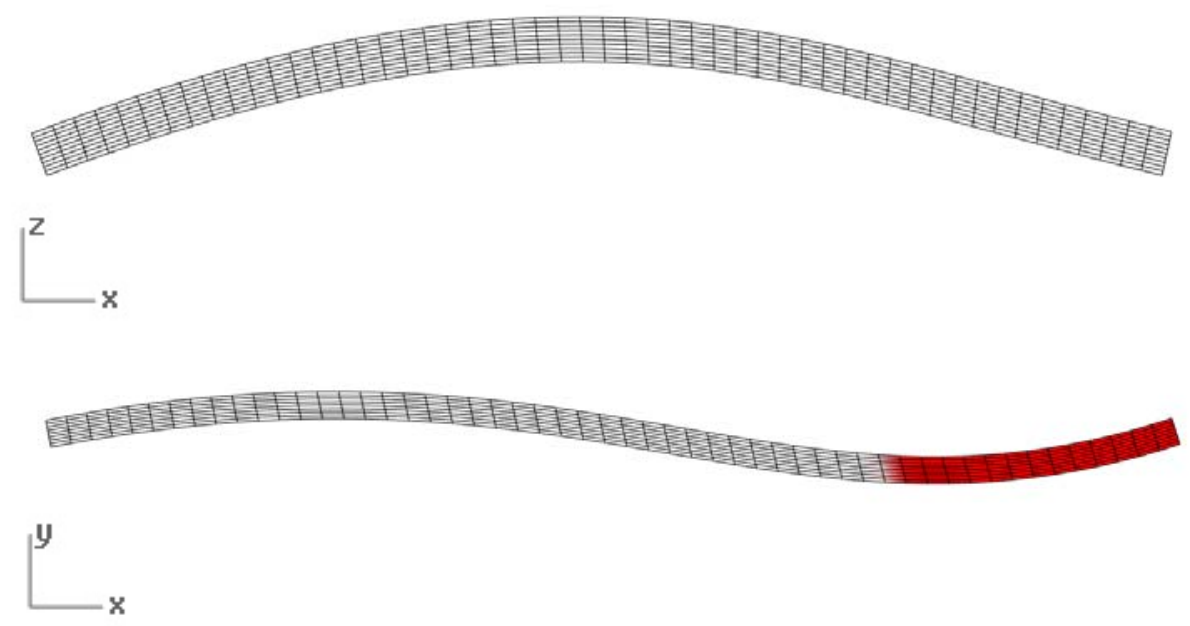

Fig. 6 Results of curvature analysis for the second test case as calculated by the programmed algorithm 
Any further consideration about the curvature analysis cannot be introduced. Benefits have to be evaluated case by case according to the strategy and machineries adopted for assembling double-curved GLT element.

According to early surveys and tests on a standard production system, the algorithm can save $30 \%$ of the operation time among product engineering-processes. For any further consideration about impacts on a standard production system of GLT from the point of view of process efficiency, authors kindly invite readers to refer to further publications $[14,15]$.

Authors remark that the programmed algorithm needs several improvements before trying to adopt it in a production system of GLT, in details:

- The curvature analysis has to be fully implemented with digital fabrication steps that has to be programmed case by case;

- The output management through digital fabrication strategy has to be validated case by case according to production flow stages in order to provide effective outputs;

- The FEM simulation step has to be fully validated;

- The algorithm has to be stress-tested by designing and engineering some prototypes, which have to satisfy different customer's needs randomly generated. Prototypes have to be mechanically tested in order to state the reliability of the algorithm.

\section{Acknowledgments}

Authors would like to express their gratitude to Prof. Maurizio Piazza from University of Trento, to Eng. Giorgio Bignotti and Eng. Oskar Rainer from Rubner Holzbau Company for their support and precious suggestions.

\section{References}

[1] ISTAT (Istituto Nazionale di Statistica (Italian Istitute of Statistics)). 2015. Censimento dell'Industria e dei Servizi 2015 (Census of Industry and Services). Accessed October

30 ,

2016. http://www.istat.it/it/censimento-industria-e-servizi. (in Italian)

[2] Wortmann, J. C. 1983. A Classification Scheme for Master Production Schedule. Efficiency of Manufacturing Systems. New York: Plenum Press.

[3] Hubers, J. C. 2010. "IFC Based BIM or Parametric Design.” In Proceedings of the International Conference on Computing in Civil and Building Engineering (ICCCBE).

[4] United States. 2016. National BIM Standard. NBIMS-US V3. Accessed October 30, 2016. https://www.nationalbimstandard.org.

[5] Jabi, W. 2013. Parametric Design for Architecture. London: Laurence King.

[6] Sacks, R., Eastman, C. M., and Lee, G. 2004. "Parametric 3D Modeling in Building Construction with Examples from Precast Concrete." Automation in Construction 13: 291-312.

[7] Shea, K., Aish, R., and Gourtovaia, M. 2005. “Towards Integrated Performance-Driven Generative Design Tools." Automation in Construction 14: 253-64.

[8] Piazza, M., Tomasi, R., and Modena R., 2005. Strutture in Legno: Materiale, Calcolo e Progetto Secondo le Nuove Normative Europee. Milano: Biblioteca tecnica Hoepli.

[9] UNI EN 14080. 2013. Strutture di legno-Legno Lamellare Incollato e Legno Massiccio Incollato-Requisiti (Glued Laminated TImber-Requirements). (in Italian)

[10] EN 1194. 1999. Timber Structures-Glued Laminated Timber-Strength Classes and Determination of Characteristics Values.

[11] Silly, G., Thiel, A., and Augustin, M. 2016. "Options for the Resource Optimized Production of Laminar load Carrying Members Based on Wood Products." In Proceedings of the World Conference on Timber Engineering 20016-WCTE 2016.

[12] DIN 1052. 2008. Entwurf, Berechnung und Bemessung von Holzbauwerken-Allgemeine Bemessungsregeln und Bemessungsregeln für den Hochbau (Design of Timber Structures-General Rules and Rules for Buildings). (in German)

[13] UNI EN 1995-1-1. 2014. Eurocodice 5-Progettazione Delle Strutture di legno-Parte 1-1: Regole Generali-Regole Comuni e Regole per gli Edifici (Eurocode 5: Design of Timber Structures-Part 1-1: General-Common Rules and Rules for Buildings). (in Italian)

[14] Pasetti Monizza, G., Matt, D. T., and Benedetti, C. 2015. "Parametric and Generative Design Techniques for Process Efficiency in Building Industry: The Case Study of Glued Laminated Timber Industry.” In Proceedings of the International Workshop on Design in Civil and 

The Case Study of Glued-Laminated Timber

Environmental Engineering 2015-DCEE 2015.

[15] Pasetti Monizza, G., Rauch, E. and Matt, D. T. n.d. "Parametric and Generative Design Techniques for
Mass-Customization in Building Industry: A Case Study for Glued-Laminated Timber”. In Proceedings of the 27th CIRP Design Conference 2017. (to be published) 